九州大学学術情報リポジトリ

Kyushu University Institutional Repository

\title{
Mathematical Modeling of Preference Intensity of Japanese Medaka for Environmental Factors in St reamf low
}

Hiramatsu, Kazuaki

Laboratory of Drainage and Water Environment, Division of Regional Environment Science, Department of Bioproduction Environmenal Science, Faculty of Agriculture, Kyushu University

Shikasho, Shiomi

Laboratory of Drainage and Water Environment, Division of Regional Environment Science, Department of Bioproduction Environmenal Science, Faculty of Agriculture, Kyushu University

https://doi.org/10.5109/24465

出版情報: 九州大学大学院農学研究院紀要. 47 (1)，pp.109-127，2002-10-30. Kyushu University バージョン：

権利関係 : 


\title{
Mathematical Modeling of Preference Intensity of Japanese Medaka for Environmental Factors in Streamflow
}

\author{
Kazuaki HIRAMATSU* and Shiomi SHIKASHO \\ Laboratory of Drainage and Water Environment, Division of Regional Environment Science, \\ Department of Bioproduction Environmental Science, Faculty of Agriculture, \\ Kyushu University, Fukuoka 812-8581, Japan \\ (Received May 14, 2002 and accepted July 12, 2002)
}

\begin{abstract}
The preference intensities of Japanese Medaka Fish (Japanese killifish, Oryzias latipes) to the three environmental factors of water depth, current velocity and cover were discussed in this paper. Mathematical models for preference intensities of Japanese Medaka to the three environmental factors were constructed in laboratory open-channel experiments. A simple genetic algorithm was newly introduced to search for the optimal functional representation of preference intensity. The models were then verified by laboratory water-tank experiments and on-the-spot examinations. The results indicated that the maximum preference level of Japanese Medaka was determined at a water depth of $9.4 \mathrm{~cm}$ and at a current velocity of $2.8 \mathrm{~cm} / \mathrm{s}$, and that the All-cover condition had a markedly high level compared with other cover conditions. The relative weights of the three environmental factors were evaluated as 0.32 for depth, 1.0 for velocity and 0.66 for cover, when the maximum weight was normalized to be unity. The weight values suggested that the environmental preferences of Japanese Medaka were not greatly affected by water depth. Judging from the good agreement between the predicted and observed distributions in considering the two factors of current velocity and cover, the two factors obviously affected the environmental preferences of Japanese Medaka.
\end{abstract}

\section{INTRODUCTION}

Increases in the number of proposed river development projects in Japan have forced hydraulic engineers to predict the level of impact to aquatic ecosystems that results from such projects. When a river is developed for agricultural, municipal and industrial purposes, the magnitude, timing, duration and quality of natural flows may be altered, thereby affecting the availability and quality of fish habitat. The engineers need to determine the necessary environment that must be maintained as fish habitat at some desired level. In this process, it is necessary to evaluate the preference intensities of river fish to environmental factors. On the other hand, fish behavior is one of the essential indicators not only for evaluating the environment following the impact of development activities on river ecosystems, but also for evaluating the functional aspects of river improvement. The quality of the present environment can be indirectly estimated by the observations of spatial distribution and/or the number of fish, together with the preference intensities of the fish to environmental factors. For the above reasons, it is important to model the preference intensities of river fish to environmental factors.

In this study, the models of preference intensities of river fish to environmental factors were experimentally constructed and verified by laboratory experiments and

* Corresponding author (E-mail: hiramatu@agr.kyushu-u.ac.jp) 
on-the--spot examinations. In the verification, spatial distributions of the fish in laboratory water tanks and an actual stream were predicted using the measurements of environmental factors together with the preference intensity models. Sekine et al. (1997) proposed a model of fish distribution based on preference intensities to environmental factors such as water temperature, cover, current velocity, turbidity and food quantities. In modeling preference intensities, we adopted this model because of the following excellent features: (a) parameter values of preference intensity curves and weight values of environmental factors can be determined separately for each factor, and (b) the values of preference intensity parameters and the weights do not need to be consequently changed when a new factor influencing fish distribution is introduced. The experimental apparatus similar to Sekine et al. (1997) was also used in this study.

While Sekine et al. (1997) dealt with the preference intensities of shiner (Tanakia limbata), Japanese Medaka Fish (Japanese killifish, Oryzias latipes) was selected as river fish for quantifying preference intensities in this study. Japanese Medaka was once one of the most popular fish inhabiting small streams and paddy fields in the countryside of Japan. However, they have been slowly disappearing in the countryside due to development activities and they are now listed as rare and endangered species in the Japanese Red Data Book, published by the Japanese Ministry of the Environment. In recent years, Japanese Medaka has been regarded as the symbolic fish for the restoration of countryside ecosystems in Japan.

First, experiments in a laboratory open channel were executed using Japanese Medaka to quantify preference intensities to the three environmental factors of water depth, current velocity and cover. These were selected as the principal factors affecting the availability and quality of the fish habitat in natural rivers. A simple genetic algorithm (SGA) was newly introduced to search for the optimal functional representation of preference intensity and to determine the parameter values of preference intensity curves. Second, experiments in laboratory water tanks, in which various environments were spatially realized, and on-the-spot examinations were then carried out to verify the preference intensities of Japanese Medaka obtained from the laboratory open-channel experiments.

\section{MATERIALS AND METHODS}

\section{Construction of preference intensity models}

\section{1) Experimental apparatus and procedures}

Laboratory experiments were conducted to construct preference intensity models to environmental factors using an open channel with side-by-side flumes shown in Fig. 1. This apparatus allowed independent manipulation of the three environmental factors of water depth, current velocity and cover in the right and left flumes. In an observation area of $30 \mathrm{~cm} \times 28.4 \mathrm{~cm}(30 \mathrm{~cm} \times 14.2 \mathrm{~cm}$ for each flume $)$, the right and left flumes were connected to each other through a narrow junction that was $6 \mathrm{~cm}$ long. The fish were confined to the observation area with the upstream and downstream stainless steel nets that allowed water to pass through unrestricted. Different environmental conditions were set independently in the right and left flumes during an experiment and the fish could swim through the junction and select the preferred flume.

A digital video camera (Sony Inc., DCR-TRV900), which was installed above the 


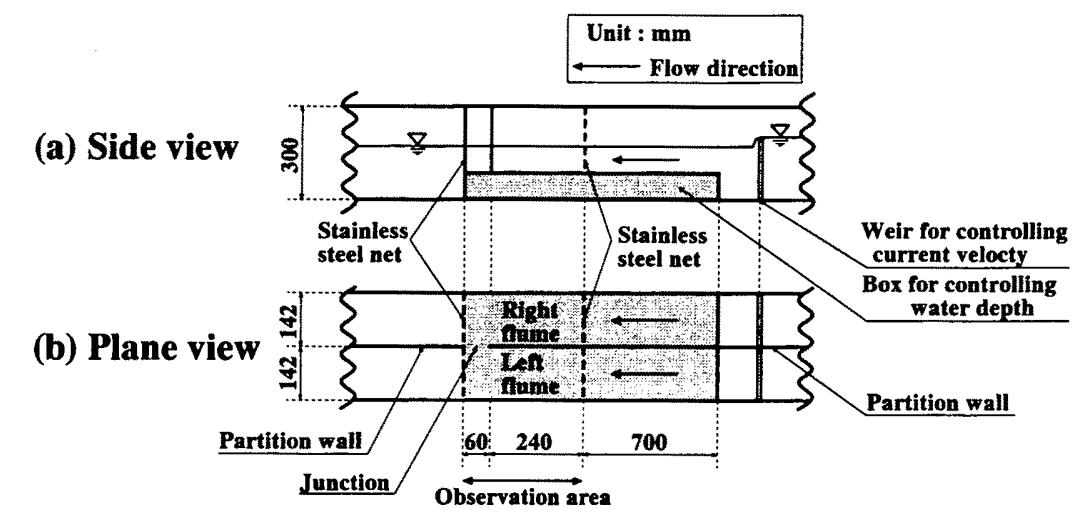

Fig. 1. Schematic diagram of apparatus for constructing preference intensity models of Japanese Medaka to environmental factors. Right and left flumes were connected to each other through a narrow junction.

center of the observation area, taped the swimming fish from about $5 \mathrm{~min}$ after their introduction into the observation area. Their distribution in the right or left flume was counted from a video image recording every minute for a 60 -minute period in one recording session. The 60 distribution data in one experiment were averaged to obtain the distribution value for the experiment.

The flumes were made of white acrylic boards in order to prevent the fish from reacting to the operator's activities and lit such that the illuminance was about $350 \mathrm{~lx}$. Water temperature was kept at $20 \pm 2{ }^{\circ} \mathrm{C}$. With the aim of independent manipulation of water depth and current velocity in the right and left flumes, the water depth was changed by attaching white acrylic boxes at the bottom of each flume and the current velocity was controlled by upstream weirs independently in both flumes as shown in Fig. 1. Current velocity was measured with a one-dimensional electromagnetic current meter at mid-water depth in the middle of each flume in the observation area without the presence of the fish.

For one set of conditions, the two groups of five fish and ten fish were examined to determine whether the number of fish affected preference intensities. Experiment was carried out three times and the results were averaged in order to eliminate the fluctuation of fish behavior in each experiment.

\section{2) Preparation of fish for experiments}

All fish used in the laboratory open-channel experiments were farmed Japanese Medaka Fish. About 150 Japanese Medaka were housed in $100 \mathrm{l}$ aquarium at $20 \pm 2^{\circ} \mathrm{C}$. The body length of the housed fish ranged from approximately $2.6 \mathrm{~cm}$ to $3.1 \mathrm{~cm}$. Randomly selected individuals among the housed fish were used in each experiment. With the aim of preventing the influence of the diurnal rhythm of fish behavior, the experiments were carried out in the morning (9:00-12:00) while flaked food was fed in the evening (18:00). One individual was not used in more than one experiment per day to prevent exhaustion. 


\section{3) Experimental conditions}

Firstly, preference intensities for the three environmental factors of water depth, current velocity and cover were separately examined in single-factor experiments.

The water-depth experiments were conducted under no-flow and no-cover conditions. Water depth in the left flume was kept at $7 \mathrm{~cm}$ and in the right it varied at 4.0,6.0, $9.0,10.5,12.0 \mathrm{~cm}$.

In the current-velocity experiments, current velocity in the left channel was set at $9 \mathrm{~cm} / \mathrm{s}$ and that in the right varied at $1.5,3.0,4.5,13.5,16.0,18.0 \mathrm{~cm} / \mathrm{s}$. Water depth was $7 \mathrm{~cm}$ in both flumes with no cover.

The cover experiments were carried out under a water depth of $7 \mathrm{~cm}$ and no-flow condition. The right flume had No-cover condition, and three cover conditions were set in the left flume of the observation area: RL-cover condition and TB-cover condition in which black acrylic sheets were mounted on both sides and on the bottom and top of the flume, respectively, and All-cover condition in which the sheets were mounted on both sides, the bottom and top of the flume.

In composite factor experiments, two factors were selected among the three factors, and the combined conditions of the two factors were set independently in the right and left flumes to quantify the relative weights between these factors. Table 1 shows the environmental conditions in the right and left flumes in the composite factor experiments. The environmental value that was proved to have the weakest relative intensity in the water-depth experiments or the current-velocity experiments was combined with the All-cover condition that had the strongest intensity in the cover experiments.

Table 1. Environmental conditions and the observations of fish distribution ratio in the right and left flumes in the composite factor experiments.

\begin{tabular}{|c|c|c|c|c|}
\hline \multicolumn{2}{|c|}{ Environmental condition } & \multirow{2}{*}{$\begin{array}{l}\text { Number } \\
\text { of fish }\end{array}$} & \multicolumn{2}{|c|}{ Distribution ratio } \\
\hline Left flume & Right flume & & $\begin{array}{l}\text { Left } \\
\text { flume }\end{array}$ & $\begin{array}{l}\text { Right } \\
\text { flume }\end{array}$ \\
\hline \multirow[t]{2}{*}{$\begin{array}{c}\text { Water depth }=7 \mathrm{~cm} \\
\text { current } \\
\text { velocity }=0 \mathrm{~cm} / \mathrm{s}, \\
\text { All-cover }\end{array}$} & $\begin{array}{c}\text { Water depth }=9 \mathrm{~cm} \\
\text { current } \\
\text { velocity }=0 \mathrm{~cm} / \mathrm{s}, \\
\text { No-cover }\end{array}$ & $\begin{array}{r}5 \\
5 \\
5 \\
10 \\
10 \\
10\end{array}$ & $\begin{array}{l}0.63 \\
0.87 \\
0.74 \\
0.71 \\
0.83 \\
0.62 \\
\end{array}$ & $\begin{array}{l}0.37 \\
0.13 \\
0.26 \\
0.29 \\
0.17 \\
0.38 \\
\end{array}$ \\
\hline & \multicolumn{2}{|c|}{ Average distribution ratio } & 0.73 & 0.27 \\
\hline $\begin{array}{l}\text { Water depth }=7 \mathrm{~cm} \text {, } \\
\begin{array}{c}\text { current } \\
\text { velocity }=9 \mathrm{~cm} / \mathrm{s}\end{array} \\
\underline{\text { No-cover }}\end{array}$ & $\begin{array}{l}\text { Water depth }=7 \mathrm{~cm} \text {, } \\
\begin{array}{l}\text { current } \\
\text { velocity }=13.5 \mathrm{~cm} / \mathrm{s}, \\
\text { All-cover }\end{array}\end{array}$ & $\begin{array}{r}5 \\
5 \\
5 \\
10 \\
10 \\
10\end{array}$ & $\begin{array}{l}0.43 \\
0.55 \\
0.59 \\
0.48 \\
0.63 \\
0.47 \\
\end{array}$ & $\begin{array}{l}0.57 \\
0.45 \\
0.41 \\
0.52 \\
0.37 \\
0.53 \\
\end{array}$ \\
\hline No-cover & \multicolumn{2}{|c|}{ Average distribution ratio } & 0.53 & 0.47 \\
\hline
\end{tabular}




\section{4) Model for a single environmental factor}

Figure 2 shows the patterns that were under consideration for the functional representation of preference intensity of a single environmental factor. In this figure, the vertical axis and the horizontal axis represent preference level $P_{j}$ and the condition of an environmental factor $j$, respectively. The pattern Type-1 is a min-max distribution, Type- -2 is a non-normal peak distribution, Type- 3 is a normal distribution and Type -4 is a discrete distribution. In each pattern, the maximum value of $P_{j}$ can be determined arbitrarily when merely considering a single environmental factor, while the maximum value of unity was adopted in this study because of its simplicity and the comparison with the preference intensity of other factors. Assuming that a ratio $R_{j}$ of the fish distribution in the right and left flumes, $i=\{$ right, left $\}$, is determined by a ratio of preference level $P_{j, i}$ for each of the three environmental factors of water depth, current velocity and cover, $j \in$ \{depth, velocity, cover\}, in the right and left flumes, $R_{j}$ is expressed in terms of $P_{j, i}$ by the equation

$$
R_{j}=P_{j, \text { right }} / P_{j, \text { left }} \text {. }
$$

Substituting the observed ratios obtained from the single-factor experiments into $R_{j}$ in equation (1), the pattern of preference intensity and its parameter values can be determined. Due to the definition of $R_{j}$ in equation (1), the minimum value of $P_{j, i}$ should be greater than zero.

In this study, a simple genetic algorithm (SGA) was newly introduced to help search

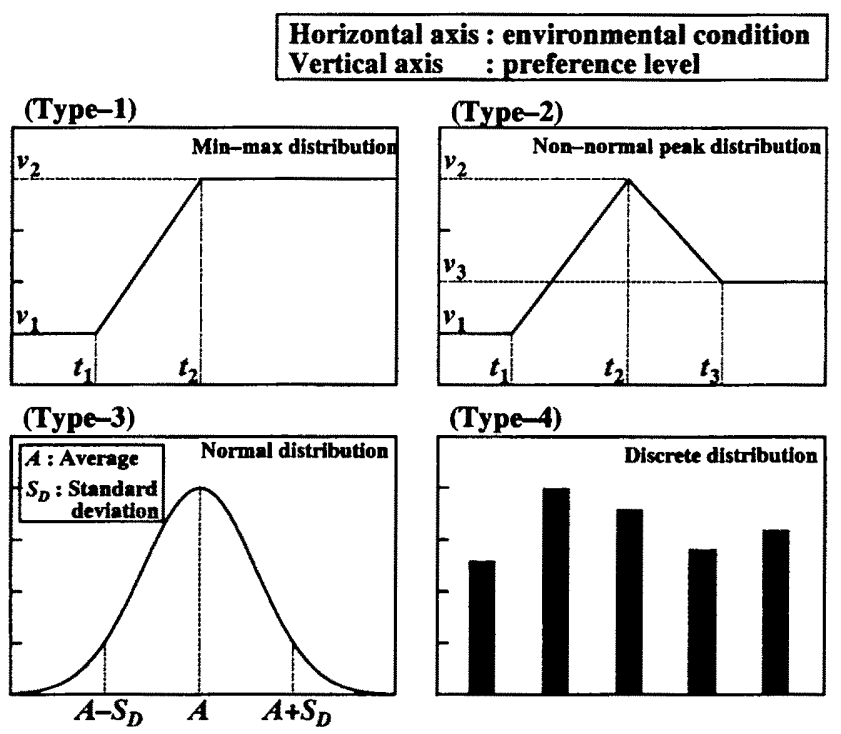

Fig. 2. Schematic illustration of functional representation of preference intensity for a single environmental factor. Type-1 is a min-max distribution, Type-2 is a non-normal peak distribution, Type- 3 is a normal distribution and Type- 4 is a discrete distribution. 
for the optimal pattern of preference intensity and the optimal parameter values. The SGA's optimizations were executed to minimize the absolute errors between the observed $R_{j} \mathrm{~s}$ of fish distribution in the single-factor experiments and the calculated $R_{j}^{\mathrm{c}} \mathrm{s}$ obtained from the preference intensity pattern.

A genetic algorithm (GA) is an optimization technique modeled after the biological processes of natural selection and evolution. The GA operates on a population of decision variable sets. Through the application of three specialized genetic operators of selection, crossover and mutation, the GA population evolves toward an optimal solution. A SGA is a basic sort of GAs. For example, a SGA has been used by Hiramatsu et al. $(1998 ; 1999)$ to determine the optimal network structure of artificial neural network models for predicting the water-stages in a tidal river and by Hiramatsu et al. (2000) to search for the optimal model parameters of fish schooling of Japanese Medaka.

\section{5) Model for composite environmental factors}

A formula to combine several $P_{j}$ s determined from the single-factor experiments and the above-mentioned optimizations is required because environmental conditions are the composite of several environmental factors in natural rivers. The combined preference level $P^{*}$ can be calculated by the forms

$$
\begin{aligned}
& P^{*}=\prod_{j=1}^{j}\left(P_{j}\right)^{\frac{W_{j}}{W_{\max }},} \\
& W_{\max }=\left\{\begin{array}{cc}
\max _{j \in Y}\left(W_{j}\right) & \mathrm{V} \neq \phi \\
\infty & \mathrm{V}=\phi, \\
V=\left\{j \mid\left(\exists i, j^{\prime}\right)\left(P_{j, i} \neq P_{j, i^{\prime}}\right)\right\},
\end{array}\right.
\end{aligned}
$$

where $W_{j}$ is the weight of preference intensity for an environmental factor $j$ and ranges from zero to unity, $W_{\max }$ is the maximum weight among the weights of environmental factors that have different preference levels in different water bodies, $\phi$ represents a null set and $\exists$ is an existential quantifier.

When a river reach with $J$ environmental factors is hypothetically divided into $I$ water bodies, the fish distribution $D_{i}$ in the $i$-th water body can be calculated by the equation

$$
D_{i}=\prod_{j=1}^{j}\left(P_{j, i}\right)^{\frac{W_{j}}{W_{\max }}} / \sum_{i=1}^{i}\left\{\prod_{j=1}^{j}\left(P_{j, i}\right)^{\frac{W_{j}}{W_{\max }}}\right\},
$$

on the assumption that fish distribution in each water body is directly proportional to the combined preference level calculated by equations (2) through (4).

Using the same assumption, the weight $W_{j}$ is determined together with the results of the composite factor experiments. For example, considering the two environmental factors of water depth and cover, $j=$ \{depth, cover\}, the ratio $R^{*}$ of the fish distribution in the two flumes, $i=\{$ right, left $\}$, is expressed in the form

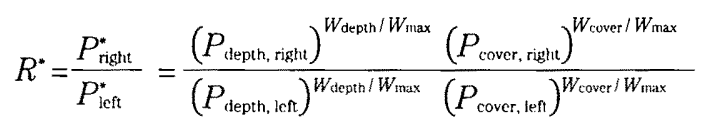

When $P_{\text {deppth, right }}$ and $P_{\text {cover, nght }}$ are not equal to $P_{\text {depth, left }}$ and $P_{\text {cover, left, }}$ respectively, the set $V$ in 
equation (4) consists of the two factors \{depth, cover\} and $W_{\max }$ corresponds to either $W_{\text {depth }}$ or $W_{\text {cover }}$ from equation (3). Substituting the observed ratio $R^{*}$ obtained from the composite factor experiments into the left side of equation (6) and the $P_{j, i}$ s calculated from the preference intensity patterns already defined in the single-factor experiments into the right side, $W_{\text {depth }}$ and $W_{\text {cover }}$ are determined in one of the two trials of $W_{\max }=W_{\text {depth }}$ and $W_{\max }=W_{\text {cover }}$ with the constraint that $W_{j}$ ranges from zero to unity.

\section{Verification of preference intensity models by laboratory experiments 1) Experimental conditions and apparatus}

Experiments in laboratory water tanks, in which various environments were spatially realized, were carried out to verify the preference intensities of Japanese Medaka obtained from laboratory open-channel experiments. Spatial distribution of the combined preference level $P^{*}$ in the water tanks was calculated by using equation (2) through (4) together with the cover condition and the measurements of water depth and current velocity in the water tanks. Fish distribution in each water body was then predicted by the calculated $P^{*}$ s and equation (5) and lastly compared with the observed distribution of Japanese Medaka.

The experimental conditions using the laboratory water tanks is summarized in Table 2 , in which the three capital letters of $\mathrm{D}, \mathrm{V}$ and $\mathrm{C}$ stand for water depth, current velocity and cover, respectively. A total of seven runs were executed to evaluate the influence of the single factor and the composite factor among the three environmental factors of water depth, current velocity and cover. Run-D, Run-V and Run-C are the single-factor experiments in which a merely single factor varies spatially in the water tanks while other factors are set to be spatially constant. Run-DV, Run-DC and Run-VC are the two-factor experiments and Run-DVC is the three-factor experiment.

The two different water tanks, Tank-1 in Fig. 3 and Tank-2 in Fig. 4, were alternatively used to suit the experimental conditions. Both tanks were made of white acrylic

Table 2. Experimental conditions and the measurements of water depth in laboratory water-tank experiments. Three capital letters of $\mathrm{D}, \mathrm{V}$ and $\mathrm{C}$ stand for water depth, current velocity and cover, respectively.

\begin{tabular}{|c|c|c|c|c|c|}
\hline Run & $\begin{array}{l}\text { Environmental } \\
\text { factors }\end{array}$ & $\begin{array}{l}\text { Experimental } \\
\text { apparatus }\end{array}$ & $\begin{array}{l}\text { Water depth (cm) } \\
\text { (D) }\end{array}$ & $\begin{array}{l}\text { Current velocity } \\
\text { (V) }\end{array}$ & $\begin{array}{l}\text { Cover } \\
\text { (C) }\end{array}$ \\
\hline Run-D & Water depth & Tank-1 & $h_{1}=14.7, h_{2}=9.5, h_{3}=4.3$ & No flow & No-cover \\
\hline Run-V & Current velocity & Tank-2 & Constant $\left(h_{0}=17.0\right)$ & Fig. 11 & No-cover \\
\hline Run-C & Cover & Tank-2 & Constant $\left(h_{0}=15.0\right)$ & No flow & $\begin{array}{l}\text { All-cover on cover } \\
\text { area in Fig. } 4\end{array}$ \\
\hline Run-DV & $\begin{array}{c}\text { Water depth } \\
\text { Current velocity }\end{array}$ & Tank-1 & $h_{1}=16.8, h_{2}=11.6, h_{3}=6.4$ & Fig. 10 & No-cover \\
\hline Run-DC & $\begin{array}{l}\text { Water depth } \\
\text { Cover }\end{array}$ & Tank-1 & $h_{1}=15.1, h_{2}=9.9, h_{3}=4.7$ & No flow & $\begin{array}{l}\text { All-cover on cover } \\
\text { area in Fig. } 3\end{array}$ \\
\hline Run-VC & $\begin{array}{l}\text { Current velocity } \\
\text { Cover }\end{array}$ & Tank-2 & Constant $\left(h_{0}=17.0\right)$ & Fig. 11 & $\begin{array}{l}\text { All-cover on cover } \\
\text { area in Fig. } 4\end{array}$ \\
\hline Run-DVC & $\begin{array}{l}\text { Water depth } \\
\text { Current velocity } \\
\text { Cover }\end{array}$ & Tank-1 & $h_{1}=16.8, h_{2}=11.6, h_{3}=6.4$ & Fig. 10 & $\begin{array}{l}\text { All-cover on cover } \\
\text { area in Fig. } 3\end{array}$ \\
\hline
\end{tabular}




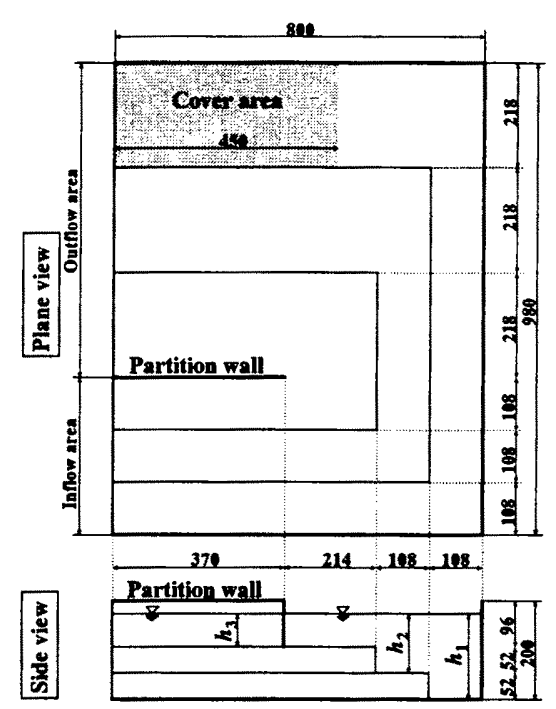

Fig. 3. Schematic diagram of apparatus for verifying preference intensity models of Japanese Medaka to environmental factors including water depth (Tank-1). Water ran into the water tank through an inflow area and flowed out through a weir along an outflow area. The three different water depthes of $h_{1}, h_{2}$ and $h_{3}$ were set in the tank.

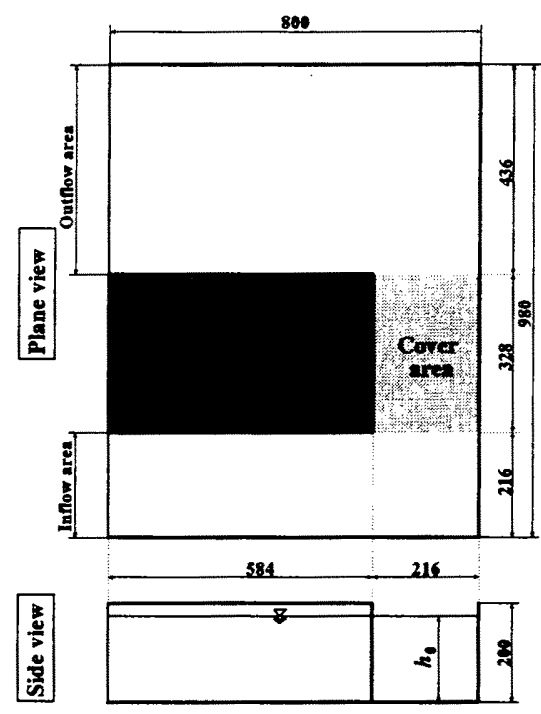

Fig. 4. Schematic diagram of apparatus for verifying preference intensity models of Japanese Medaka to environmental factors not including water depth (Tank-2). Water ran into the water tank through an inflow area and flowed out through a weir along an outflow area. The tank had merely one water depth $h_{0}$.

boards. Screens were put up around the tanks in order not to disturb fish movernent as a result of the operator's activities. In the experiments concerning current velocity, water ran into the water tank through the inflow area from a lower reservoir tank by pump, circulated in the water tank counterclockwise in Figs. 3, 4 and flowed out through a weir along the outflow area to the lower reservoir tank. In Tank-1, used in the experiments on water depth, the three different water depths of $h_{1}, h_{2}$ and $h_{3}$ were set by attaching the white acrylic boxes on the tank bottom, while Tank- 2 had the merely one water depth $h_{0}$ and was used in the experiments that did not concern the water depth. In the experiments concerning cover, the All-cover condition was set on the cover area in the water tanks by black acrylic sheets.

The fish used in the laboratory water-tank experiments were the same Japanese Medaka as in the laboratory open-channel experiments. Furthermore, the experiments were carried out at the same time slot as that in the laboratory open-channel experiments. The water tanks were lit at an illuminance of about $350 \mathrm{~lx}$. The digital video camera installed at $245 \mathrm{~cm}$ above the water surface in the center of the water tank was utilized for the measurement of current velocity and the observation of fish distribution, which are described later. 


\section{2) Measurement of water depth and current velocity}

Prior to the experiments using the swimming Japanese Medaka, the measurements of water depth and current velocity were conducted without the presence of the fish.

Water depth was measured at several points in the water tank and the average values were used in calculating the preference level $P^{*}$.

A method of Particle Image Velocimetry (PIV) was introduced to easily measure the spatial distribution of current velocity in the water tanks. The running water mixed with a small amount of aluminum powder was visualized by a light sheet of 15-watt Ar laser and taped by the digital video camera. Black acrylic sheets were stuck to the bottom of the water tanks to avoid the reflection of the laser light. Instantaneous images were taken from the recorded video images and then entered into a personal computer at $1 / 5$-second intervals for a $120-$ second period in one recording session. The two-dimensional velocity vectors at 1/5-second intervals were calculated on a horizontal plane by PIV software (Flow-vec32, Library Inc.) and then averaged to obtain the time-averaged velocity vectors for the recording session. Executing the above-mentioned measurement at the lower layer $\left(h_{1} / 6\right.$ or $\left.h_{0} / 6\right)$, the middle layer $\left(h_{1} / 2\right.$ or $\left.h_{0} / 2\right)$ and the upper layer $\left(5 h_{1} / 6\right.$ or $\left.5 h_{\mathrm{o}} / 6\right)$, we obtained the depth-averaged velocities that were used in calculating the preference level $P^{*}$.

\section{3) Observation of fish distribution in water tanks}

In each experiment, we used 120 randomly selected individuals among the housed fish. The digital video camera taped the swimming fish from about 5 minutes after their introduction into the water tank. The water area in Tank-1 and Tank-2 was hypothetically divided into the small water bodies shown in Fig. 5 and the fish distribution in each water body was calculated from a video image recording every 10 minutes for a $100-$ minute period in one recording session. The 10 distribution data in one experiment wereaveraged to obtain the distribution values for the experiment.

(a)

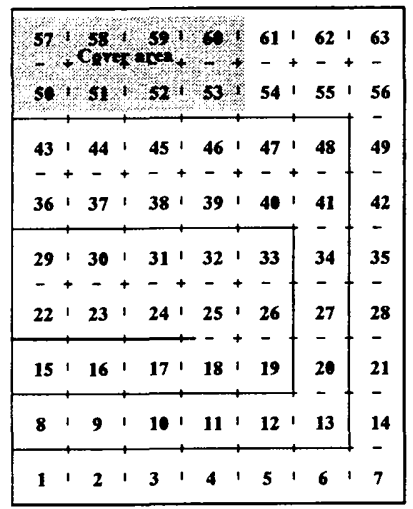

(b)

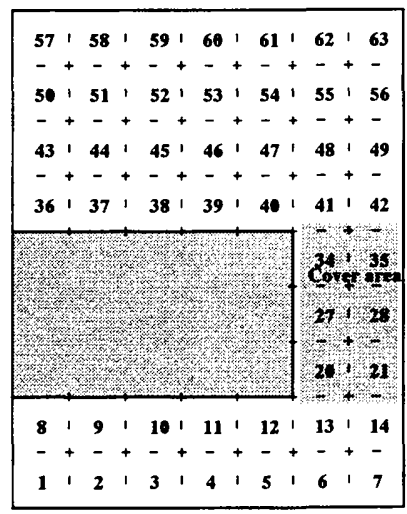

Fig. 5. Definition of water bodies and a cover area in (a) Tank-1 and (b) Tank-2. Distribution of Japanese Medaka was counted in each water body. 


\section{Verification of preference intensity models by on-the-spot examinations}

On-the-spot examinations in a small irrigation canal located in Shingu Town, Fukuoka Prefecture, Japan, have been also made for the verification of the preference intensities of Japanese Medaka obtained from the laboratory open-channel experiments. The distributions of Japanese Medaka and the three environmental factors of water depth, current velocity and cover were measured and the observed fish distribution was compared with the predicted fish distribution calculated by equations (2) through (5) and by the measurements of the three environmental factors. Photograph 1 shows the examined reach looked down from the upstream end. The reach had a length of about $72 \mathrm{~m}$ and was a moderately low-gradient canal with precast concrete block lining and with a bottom width of about $3 \mathrm{~m}$. Sand and gravel accumulated on the bottom that was partly covered by vegetation as shown in. Photo. 1 .

The examinations were conducted in the morning (10:00-12:00) on the two sunny days of September $28^{\text {th }}$ and October $12^{\text {th }}$ in 2001 . On both days, we firstly observed the distribution of Japanese Medaka prior to the measurements of the environmental factors to avoid possible change of fish distribution due to the environmental factor measurements. Water temperatures on September $28^{\text {th }}$ and October $12^{\text {th }}$ were $28^{\circ} \mathrm{C}$ and $21^{\circ} \mathrm{C}$, respectively. In the following, the data on October $12^{\text {th }}$ were used for the verification study because the water temperature was too high on September $28^{\text {th }}$ compared with that in the laboratory experiments.

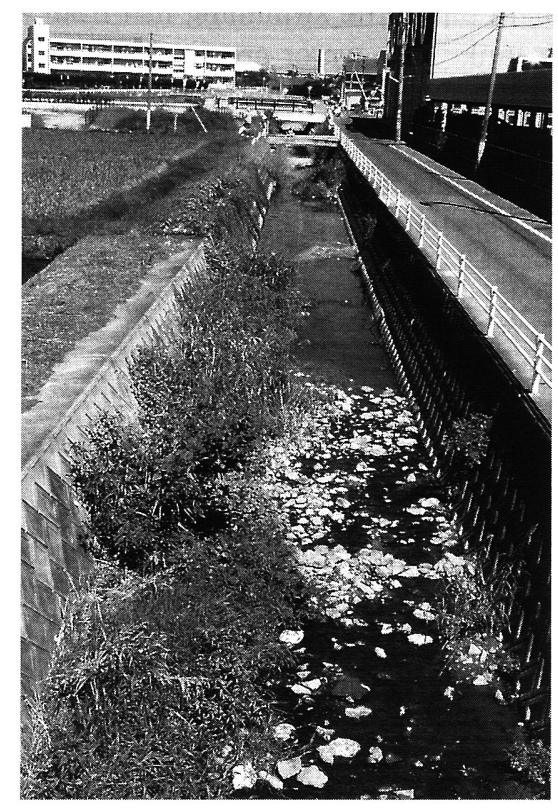

Photo.1. Photograph of examined reach looked down from the upstream end. The reach had a length of about $72 \mathrm{~m}$ and was a moderately low-gradient canal with precast concrete block lining and with a bottom width of about $3 \mathrm{~m}$. Sand and gravel accumulated on the bottom that was partly covered by vegetation. 
The examined reach was hypothetically divided into small water bodies with a length of $1.5 \mathrm{~m}$ and the observations of fish distribution and the measurements of environmental factors were carried out at each water body.

The distribution of Japanese Medaka was determined by counting the number of the fish in each water body from the levee of the canal in order to prevent the fish from reacting to the observer's activities. A series of observations from the upstream end through the downstream end was carried out four times and the results were averaged.

We measured water depth and current velocity typical of that in each water body. Water depth was measured with a stainless steel ruler while a portable propeller current meter and a float were used for measuring the relatively fast and the slow current velocities, respectively. The cover condition was determined among No-cover, RL-cover, TB-cover and All-cover by observing the shape of vegetation cover typical of that in each water body.

\section{RESULTS AND DISCUSSION}

\section{Preference intensity models}

Figure 6 shows the distribution ratios of the fish in the right or left flume in the single-factor experiments conducted in the laboratory open channel. The water depth in the left flume was $7 \mathrm{~cm}$ in the water-depth experiments (Fig. 6 (a)), the current velocity in the left flume was $9 \mathrm{~cm} / \mathrm{s}$ in the current-velocity experiments (Fig. 6 (b)) and the No-cover condition was set in the right flume in the cover experiments (Fig. 6 (c)). The distribution ratios indicate that Japanese Medaka prefers deeper water depth, slower current velocity and relatively dark places. Because the distribution ratios in one set of conditions are slightly scattered while the differences between the five fish and the ten fish experiments are not definitely found; all distribution ratios in one set of conditions are averaged to obtain the distribution value for the modeling of preference intensity.

Figures 7, 8, 9 indicate the preference intensity patterns optimized by the SGA with the average distribution ratios. The comparison of the observed distribution ratios with the predicted distribution ratios calculated by the optimal intensity models are also shown in these figures. The preference intensity pattern of Type-2 is selected for water depth and the maximum preference level is given at a water depth of $9.4 \mathrm{~cm}$. The pattern Type- 2 is also selected for current velocity and the maximum level is given at $2.8 \mathrm{~cm} / \mathrm{s}$. In the cover experiments, the discrete distribution Type-4, in which the intensity levels are separately determined for each condition without the SGA optimization, is inevitably used. All-cover condition is on a markedly high level compared with other conditions.

The composite factor experiments were carried out in the laboratory open channel under the two sets of conditions. The distribution ratios in the right and left flumes and their averages are shown in Table 1. Using the average distribution ratios, the relative weights necessary for evaluating the combined preference level of the three environmental factors, $j=\{$ depth, velocity, cover $\}$, were estimated from calculation as

$$
W_{\text {depth }}=0.32, W_{\text {velocity }}=1.0, W_{\text {cover }}=0.66 \text {, }
$$

when the maximum weight was normalized to be unity. Knowledge of the weight values enables us to compare the preference intensities of the environmental factors with each 


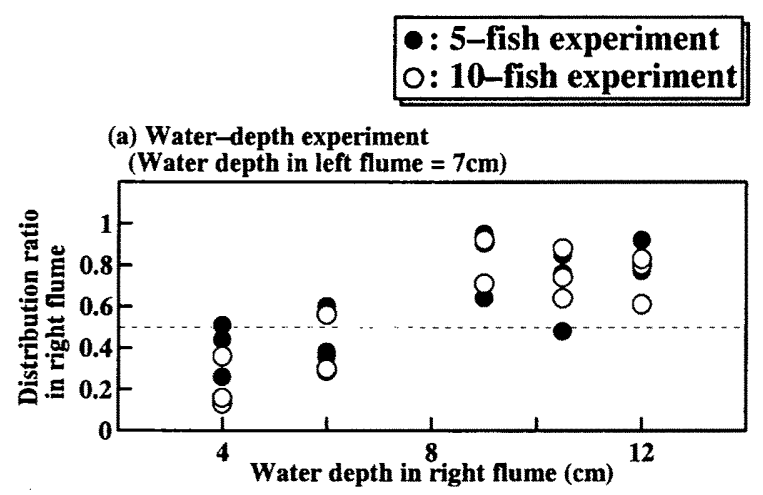

(b) Current-velocity experiment

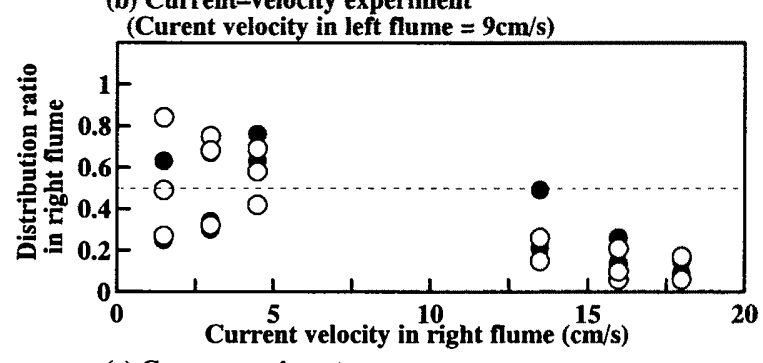

(c) Cover experiment

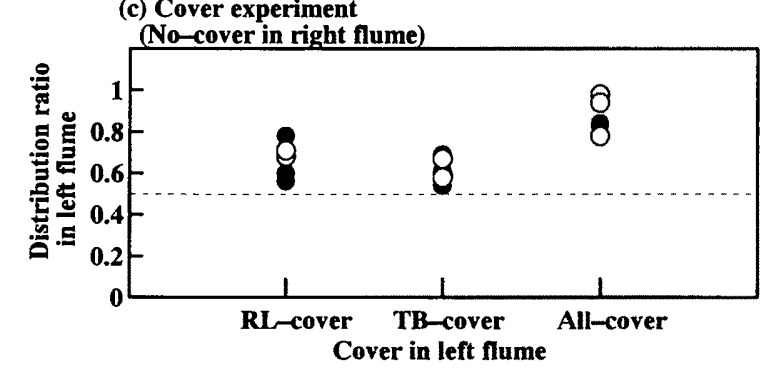

Fig. 6. Distribution ratios of Japanese Medaka in the right or left flume in single-factor experiments conducted in the laboratory open channel. Two groups of five fish and ten fish were examined in the experiments.

other. Preference intensities in the cover experiments seem to show a clear difference among cover conditions judging from the results of the single-factor experiments in Figs. $7,8,9$, but the weight values reveal that the current velocity has the strongest preference intensity among the three environmental factors.

\section{Prediction of fish distribution}

The spatial distribution of the combined preference level $P^{*}$ in the laboratory water tanks was calculated by using equation (2) through (4) together with the cover condition and the measurements of the depth-averaged current velocity in Figs. 10, 11 and the 
(a) Distribution ratio (O: Observed, $\longrightarrow$ : Calculated)

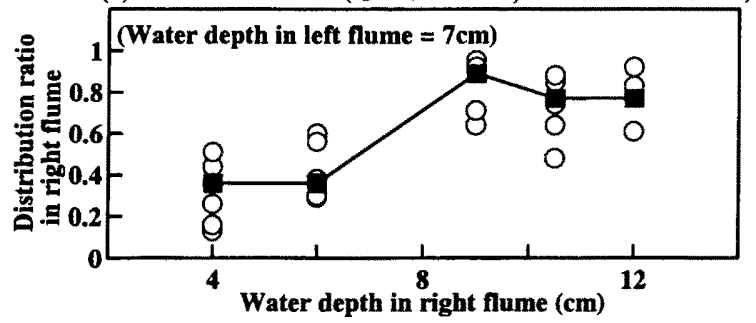

(b) Preference level distribution (Type-2)

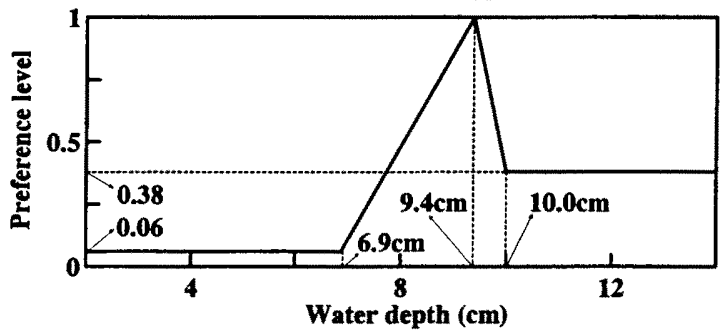

Fig. 7. Preference intensity pattern for water depth. Type-2 was selected by the optimization using the SGA. The comparison of the observed distribution ratios with the predicted distribution ratios calculated by the optimal intensity pattern are also shown in the top.

(a) Distribution ratio (O: Observed, $\rightarrow-$ : Calculated)

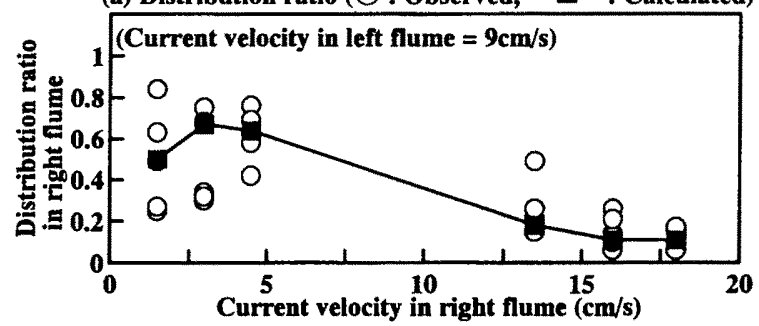

(b) Preference level distribution (Type-2)

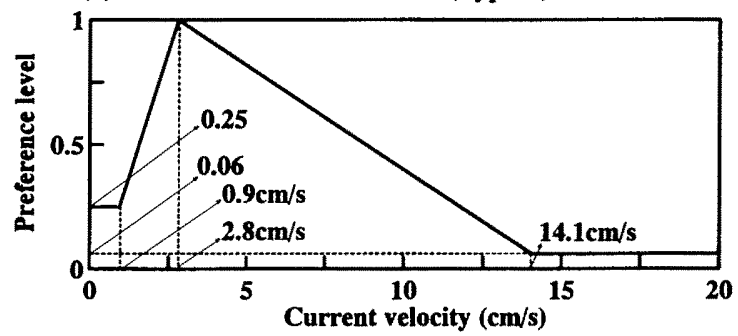

Fig. 8. Preference intensity pattern for current velocity. Type- 2 was selected by the optimization using the SGA. The comparison of the observed distribution ratios with the predicted distribution ratios calculated by the optimal intensity pattern are also shown in the top. 


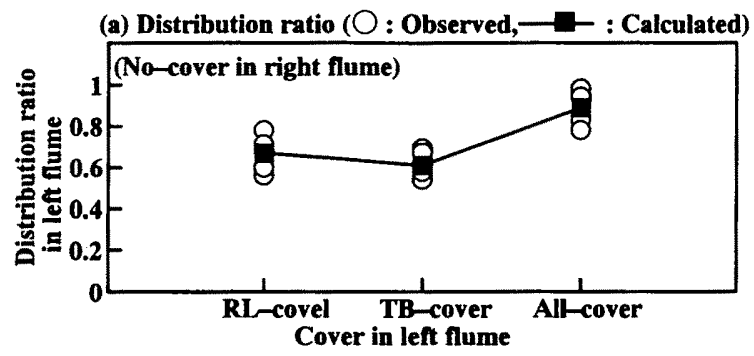

(b) Preference level distribution (Type-4)

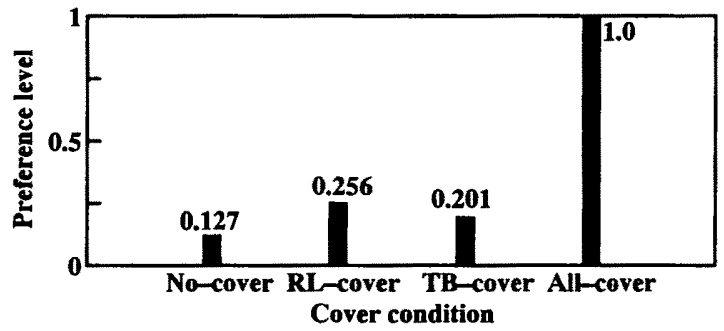

Fig. 9. Preference intensity pattern determined for cover. The discrete distribution Type-4 was inevitably selected without the SGA optimization. The comparison of the observed distribution ratios with the predicted distribution ratios calculated by the optimal intensity pattern are also shown in the top.

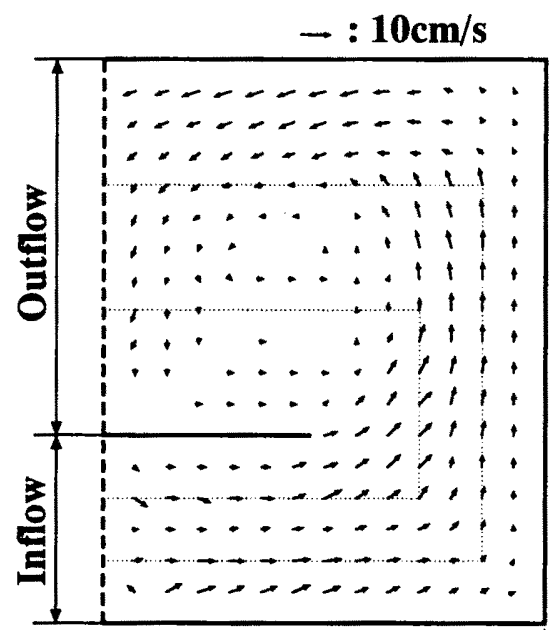

Fig. 10. Depth-averaged current velocities measured by PIV and used in calculating the spatial distribution of the combined preference level $P^{*}$ in Tank-1.

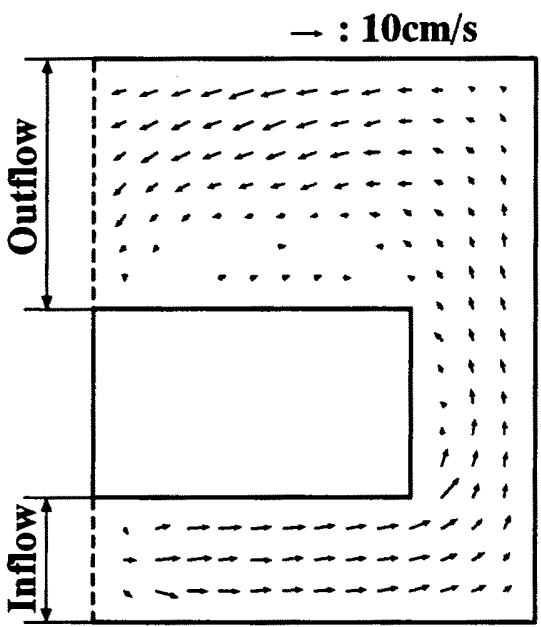

Fig. 11. Depth-averaged current velocities measured by PIV and used in calculating the spatial distribution of the combined preference level $P^{*}$ in Tank-2. 
(a) Run-D (Water depth, Tank-1)

(a)erved

0 : Predicted

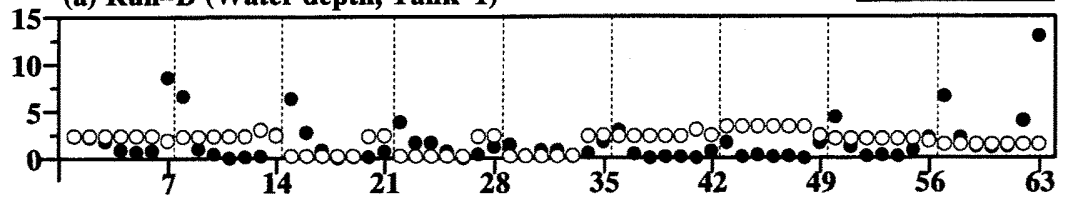

(b) Run-V (Current velocity, Tank-2)

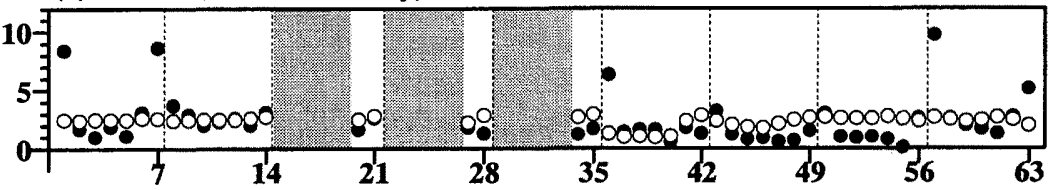

(c) Run-C (Cover, Tank-2)

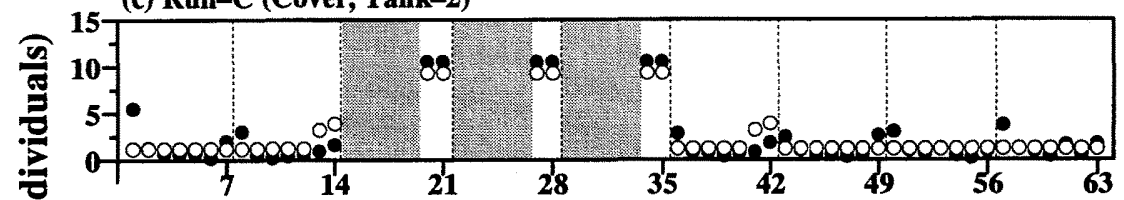

(d) Run-DV (Water depth+Current velocity, Tank-1)

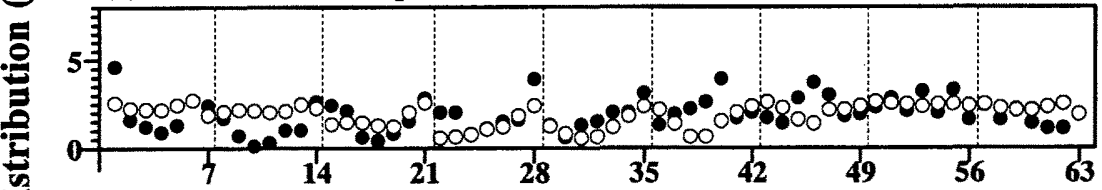

(e) Run-DC (Water depth+Cover, Tank-1)

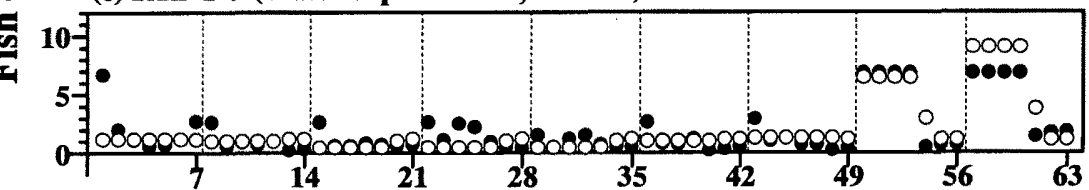

(f) Run-VC (Current velocity+Cover, Tank-2)

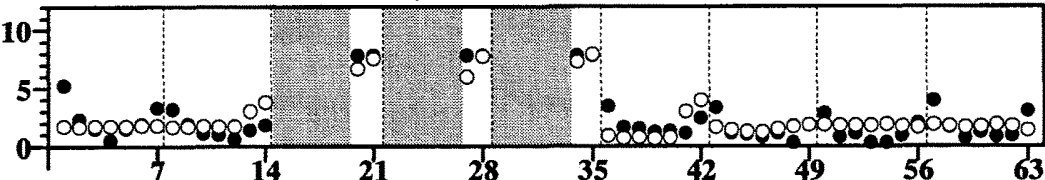

(g) Run-DVC (Water depth+Current velocity+Cover, Tank-1)

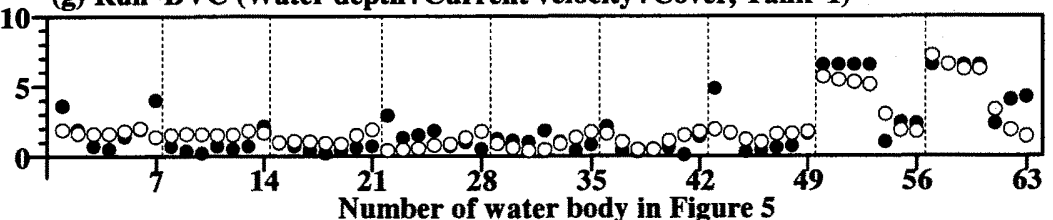

Fig. 12. Comparison of the predicted distributions with the observed distributions in the seven runs. The horizontal axis represents the consecutive numbers of water bodies defined in Fig. 5. 


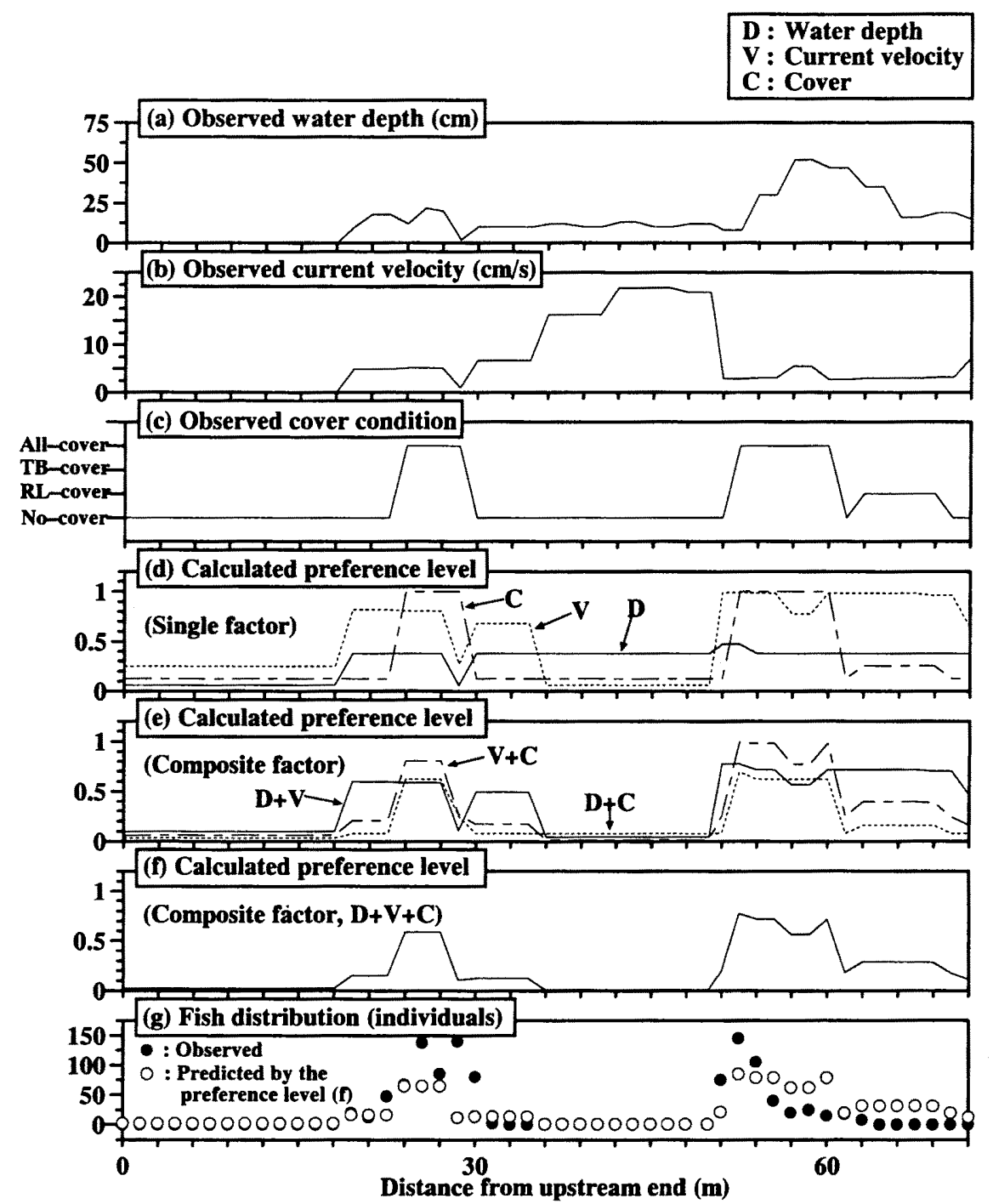

Fig. 13. Results of the on-the-spot examinations executed in Shingu Town, Fukuoka Prefecture, Japan. The measurements of (a) water depth, (b) current velocity and (c) cover, (d) the preference levels calculated for each factor, the combined preference levels obtained by considering (e) two factors and (f) all three factors and (g) the comparison of the observed fish distribution with the predicted fish distribution calculated by (f). 
water depth in Table 2. The fish distribution in each water body was then predicted by the calculated $P^{*} \mathrm{~S}$ and equation (5). The predicted fish distribution was compared with the observed distribution for verifying the preference intensity models of Japanese Medaka. Figure 12 indicates the comparison of the predicted distributions with the observed distributions in the seven runs. The horizontal axis represents the consecutive numbers of water bodies defined in Fig. 5. Among the single-factor experiments of Run-D, Run- $\mathrm{V}$ and Run- $\mathrm{C}$, the agreement between the predicted and observed distributions in Run-D is slightly worse than those in Run-V and Run-C, which reveals that the environmental preference of Japanese Medaka is not greatly affected by water depth. This is also suggested by the weight values of the three environmental factors: $W_{\text {velocity }}>W_{\text {cover }}>W_{\text {depth. }}$. Judging from the good agreement between the predicted and observed distributions in the runs connected with the two factors of current velocity and cover, the two factors obviously affect the environmental preference of Japanese Medaka.

The preference intensity models were also verified by the on-the-spot examinations in Fig. 13. Using the measurements of the three environmental factors in Fig. 13 (a), (b), (c), the preference levels in Fig. 13 (d) are calculated for each of the three environmental factors based on the assumption that a merely single factor is varied in the canal reach and other factors are kept spatially constant. The combined preference levels in Fig. 13 (e) and in Fig. 13 (f) are obtained by considering the two factors and all three factors, respectively. The observed fish distribution is shown in Fig. 13 (g) with the predicted distribution calculated by the combined preference level in Fig. 13 (f). The total number of individual of Japanese Medaka is 1,042 in the examined reach. The agreement is generally good between the observed and predicted fish distribution in Fig. 13 (g) while Fig. 13 (d) reveals that the environmental preference of Japanese Medaka is not greatly affected by water depth.

Iwamatsu and Yamataka (1996) executed on-the-spot examinations in 180 spots such as river, canal, stream, pond and paddy field in Aichi Prefecture, Japan, from April through November in 1994. They investigated whether or not Japanese Medaka inhabited each spot together with the measurement of environmental factors. Table 3 indicates the averages and the standard deviations of water depth and current velocity for two groups of the spot where Japanese Medaka inhabited or not. The results of the significance test ( $t$-test) in this table reveal that water depth is not the important factor for the habitat

Table 3. Averages and standard deviations of water depth and current velocity for two groups of the spot where Japanese Medaka inhabited or not in on-the-spot examinations in Aichi Prefecture, Japan (Iwamatsu and Yamataka, 1996). The significance test ( $t$-test) reveals that the difference between the averages of water depth in two groups is not significant but the averages of current velocity are significantly different.

\begin{tabular}{|c|c|c|c|}
\hline \multirow{2}{*}{$\begin{array}{l}\text { Environmental } \\
\text { factor }\end{array}$} & \multicolumn{2}{|c|}{ Average, standard deviation (number of spot) } & \multirow{2}{*}{$\begin{array}{l}\text { Significance test } \\
(t \text {-test })\end{array}$} \\
\hline & Inhabited & Not inhabited & \\
\hline $\begin{array}{l}\text { Water depth } \\
(\mathrm{cm})\end{array}$ & $24.69,2.24(82)$ & $22.05,2.16(98)$ & $\begin{array}{l}\text { Not significant } \\
\quad(p>0.05)\end{array}$ \\
\hline $\begin{array}{l}\text { Current velocity } \\
(\mathrm{cm} / \mathrm{s})\end{array}$ & $1.62,0.37(82)$ & $7.11,0.86(98)$ & $\begin{array}{l}\text { Significantly different } \\
\qquad(p<0.001)\end{array}$ \\
\hline
\end{tabular}


environment of Japanese Medaka. This corresponds to the results of the laboratory experiments in this study. The average current velocity in the spots Japanese Medaka inhabited is $1.62 \mathrm{~cm} / \mathrm{s}$ while the maximum preference level was given at $2.8 \mathrm{~cm} / \mathrm{s}$ in the laboratory experiments in this study. Iwamatsu and Yamataka (1996) measured current velocity by floating a ping-pong ball with a string of $4 \mathrm{~m}$ length. Because this method is very likely to measure the current velocity slower than the true value, the current velocity of $2.8 \mathrm{~cm} / \mathrm{s}$ that gave the maximum preference level in this study is almost the same as the average current velocity in the spots Japanese Medaka inhabited in their study.

\section{CONCLUSIONS}

The preference intensity models of Japanese Medaka to the three environmental factors of water depth, current velocity and cover were discussed in this paper.

Firstly, the preference intensity models were constructed in laboratory open-channel experiments. In modeling preference intensities to environmental factors, we adopted Sekine's model and a simple genetic algorithm was newly introduced to search for the optimal functional representation of preference intensity and to determine the parameter values of the preference intensity curves. The results indicated that the maximum preference level was given at a water depth of $9.4 \mathrm{~cm}$ and at a current velocity of $2.8 \mathrm{~cm} / \mathrm{s}$, and that the All-cover condition had a markedly high level compared with other cover conditions. The relative weights necessary for calculating the combined preference level of the three environmental factors were evaluated as $W_{\text {depth }}=0.32, W_{\text {velocity }}=1.0$ and $W_{\text {cover }}=0.66$, when the maximum weight was normalized to be unity.

Next, the models were then verified by laboratory water-tank experiments and on-the-spot examinations. In the verification, the spatial distributions of the fish in the laboratory water tanks and in the actual stream were predicted using the measurements of the environmental factors together with the preference intensity models obtained from the open-channel experiments. The results revealed that the environmental preference of Japanese Medaka was not greatly affected by water depth, which was also suggested by the weight values of the three environmental factors: $W_{\text {velocity }}>W_{\text {cover }}>W_{\text {depth }}$. Judging from the good agreement between the predicted and observed distributions in considering the two factors of current velocity and cover, the two factors obviously affect the environmental preference of Japanese Medaka.

\section{ACKNOWLEDGEMENTS}

The authors wish to thank Mr. Kei Nakayama, Mr. Koyu Murai and Miss Kaori Honda of Graduate School of Bioresource and Bioenvironmental Sciences, Kyushu University, for their vital help in conducting the laboratory experiments and the on-the-spot examinations. Partial financial support for this study was provided by a Grant-in-Aid for Scientific Research from the fund of the Japan Society for the Promotion of Science (no.12460107, no.14656089, no.14560201).

\section{REFERENCES}

Sekine, M., T. Imai and M. Ukita 1997 A model of fish distribution in rivers according to their preference 
for environmental factors. Ecol. Model., 104: 215-230

Hiramatsu, K., S. Shikasho and K. Mori 1998 The use of genetic algorithm and artificial neural network for the short-term prediction of water-stages in a tidal river. Proceedings of the 11th Congress of Asia and Pacific Division of the International Association for Hydraulic Research: 587-595

Hiramatsu, K., S. Shikasho and K. Mori 1999 Nonlinear prediction of river water-stages by feedback artificial neural network. J. Fac. Agr., Kyushu Univ., 44: 137-147

Hiramatsu, K., S. Shikasho and K. Mori 2000 Mathematical modeling of fish schooling of Japanese Medaka using basic behavioral patterns. J. Fac. Agr., Kyushu Univ., 45: 237-253

Iwamatsu, T. and I. Yamataka 1996 A research of the habitat area of the Medaka Oryzias latipes in Aichi Prefecture. The Bulletin of Aichi Univ. of Education, 45 (Natural Science): $41-56$ (in Japanese) 